\title{
Understanding the link between older volunteers' resources and motivation to volunteer
}

\section{Andrea Principi, Joop Schippers, Gerd Naegele, Mirko Di Rosa \& Giovanni Lamura}

To cite this article: Andrea Principi, Joop Schippers, Gerd Naegele, Mirko Di Rosa \& Giovanni Lamura (2016) Understanding the link between older volunteers' resources and motivation to volunteer, Educational Gerontology, 42:2, 144-158

To link to this article: http://dx.doi.org/10.1080/03601277.2015.1083391

Accepted author version posted online: 16

Sep 2015.

Published online: 16 Sep 2015.

Submit your article to this journal $[\pi$

Џلll Article views: 434

Q View related articles

View Crossmark data

Citing articles: 2 View citing articles $\longleftarrow$ 


\title{
Understanding the link between older volunteers' resources and motivation to volunteer
}

\author{
Andrea Principi ${ }^{a}$, Joop Schippers ${ }^{b}$, Gerd Naegele ${ }^{c}$, Mirko Di Rosa ${ }^{d}$, and Giovanni Lamura ${ }^{a}$ \\ ${ }^{a}$ Centre for Socio-Economic Research on Ageing, National Institute of Health and Science on Aging (INRCA), Ancona,

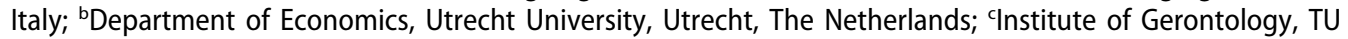 \\ Dortmund University, Dortmund, Germany; ${ }^{d}$ Scientific Direction, National Institute of Health and Science on Aging \\ (INRCA), Ancona, Italy
}

\begin{abstract}
The purpose of this study was to investigate the impact of older volunteers' available human, social, and cultural capital on their motivational forces to volunteer, measured through the Volunteer Function Inventory. A large European database of 955 older volunteers (i.e., aged 50+) was employed, and Seemingly Unrelated Regressions showed that older volunteers have different motivations according to different sets of individual resources. Furthermore, lower amounts of human and social capital (e.g., low educational level, poor health, being widowed, divorced or single) are associated with a higher propensity to volunteer to enhance one's own self-esteem, to avoid thinking of personal problems, and for social reasons. These results have important implications for policy makers and voluntary organizations if they want to enhance volunteering among older people with less resources, i.e., that are more at risk of social exclusion. For example, according to the results of this study, policy makers could consider developing more tailored opportunities for involving older volunteers with low educational level, poor health, widowed, divorced, or single. They could do this by underlying that volunteering offers possibilities to satisfy motivational needs important to the, elderly, e.g., to increase self-esteem, to deal with personal problems in a better way, and to have satisfying social contacts.
\end{abstract}

\section{Introduction}

Against the demographic aging scenario, the concept of active aging has become central in European policies (Zaidi \& Stanton, 2015). In an active aging perspective, older people are considered a resource for society. By aging actively, older individuals could enhance their quality of life (World Health Organization [WHO], 2002), making it clear that to age actively is of benefit not only to society as a whole but also to older individuals. Volunteering has been recognized as an important field in which active aging can be accomplished (Walker, 2011; Zaidi \& Stanton, 2015). This is because it allows older adults to remain active by enjoying social recognition and integration that also lead to health-related benefits. Hence, voluntary organizations and policy makers need to increase their knowledge on how to possibly increase the level of volunteering among older people. Relative to the latter aim, we have identified two main fields of available studies in the literature: One is a body of studies dealing with determinants of volunteer participation in older age. These are studies on individual resources that are mainly needed for participating in volunteer activities. The other main field is studies reporting information on the kind of motivations driving volunteer participation in older age. Because individual resources and motivations are two key elements to

CONTACT Andrea Principi $\otimes$ a.principi@inrca.it $\Theta$ Centre for Socio-Economic Research on Ageing, National Institute of Health and Science on Ageing (INRCA), via S. Margherita 5, Ancona 60124, Italy.

(c) 2016 Taylor \& Francis 
explain volunteering of older people, both of these study fields have generated useful information for the benefit of voluntary organizations and policy makers. However, there is very scarce evidence in the literature on the existing relationship between individual resources for volunteer work and volunteer motivation. This is despite the fact that knowledge on the nature of this relationship can provide additional crucial information for stakeholders and policy makers. For this reason, the main aim of this article is to study the relationship between older volunteers' resources and their motivation to volunteer.

\section{Resources and volunteering in older age}

Previous studies on volunteering in older age (even on volunteering at all ages), often showed that volunteers have specific characteristics. They are on average more educated, wealthier, and healthier than nonvolunteers (Choi, 2003; Erlinghagen \& Hank, 2006; Morrow-Howell, 2007; Warburton, Terry, Rosenman, \& Shapiro, 2001; Wymer, 1999). Volunteers are also typically married and likely to be working in the labor market; they have a large number of friends and a considerable sense of religiosity (Institut für Demoskopie Allensbach \& Generali Zukunftsfonds, 2013; Mutchler, Burr, \& Caro, 2003; Wymer, 1999). Thus, it was argued that the extent to which these characteristics apply to individuals may affect the decision to be a volunteer. In this respect, Wilson and Musick (1997) suggested an interesting overarching approach to include all the above in a unique conceptual framework. On the basis of the premise that formal volunteering is a productive activity, that it is a collective action, and that it implies an ethical relationship. Thus, they argued that volunteering is structurally influenced by the availability of three specific kinds of individual capital: human capital (i.e., resources that strengthen the participation in productive activities); social capital (i.e., resources that encourage the participation in collective actions); and cultural capital (i.e., attitudes that favor ethical behavior and a culture of benevolence).

Examples of resources constituting human capital are those that feed a dominant status in productive activities such as high educational level, qualifications, income, and health status. Economists generally consider income as an effect of human capital, (Becker, 1964; Polachek \& Siebert, 1993). But according to Wilson and Musick's theory, income should be treated as an indicator of human capital because it indicates a dominant status that qualifies individuals for voluntary work (Smith, 1994). Resources considered as social capital are those that favor social contacts, thus facilitating the participation in volunteering as a collective action. For example, having several social interactions, access to networks or children in the family, and working in the labor market may draw people into community activities (Wilson \& Musick, 1997).

The third set of resources, cultural capital, refers to attitudes regarding values or moral and ethic components that may be conceptualized as usable resources to be spent in volunteering (Wilson \& Musick, 1997). Cultural capital is usually measured with the sense of religion, because the latter may be considered as a source of the culture of benevolence. Relative to formal volunteering, on investigating a sample of Americans aged 25 years or more, Wilson and Musick found an overall support to their theory.

Several studies have relied on Wilson and Musick's theory to investigate volunteering in older age. For example, Tang (2006) used three waves of data from Americans aged 25 years and older. Tang not only investigated whether human, social, and cultural resources affected volunteering, but also analyzed birth cohort differences regarding the impact of individual resources on volunteering. Wilson and Musick hypothesized that life course changes may affect individual resources, and, hence, volunteering in terms of hours spent on volunteer work and of the number of organizations in which to volunteer. Tang (2006) operationalized human capital with education, income, self-rated health and functional ability; social capital with informal social integration, number of friends and social support; and cultural capital with church attendance and spiritual support (Tang, 2006). This study confirmed Wilson and Musick's result that volunteering depends on the available resources. It also added interesting insights because it found a different impact of resources on volunteering 
according to age, highlighting how high education, good health conditions, having a good informal social network, and attending churches are particularly important for volunteering of older people.

Okun and Michel (2006) dealt with determinants of volunteering of older people by relying on a cross-sectional sample of $60+$ in the United States. This study included human (education, income, health, as well as employment condition); social (number of children, contacts with friends, marital status, and ties with organizations like unions, sports, or social groups, etc.); and cultural capital (generative concern, church attendance, and spirituality). Furthermore, among other possible determinants, they added sense of community (SOC) that was measured through a range of agreement or disagreement to four statements on the individual's attachment to the community. They found education, organizational ties, generative concern, church attendance, and sense of community to have a role in predicting volunteering of older people. High working hours and being divorced, separated, or widowed were found to have a role in abstaining from volunteering.

Other insights from resource theory have come from McNamara and Gonzales (2011) on U.S. people of $50+$. They used different waves of data aiming to demonstrate that the availability of resources affects not only the decision to start volunteering and the intensity of volunteering (in terms of hours spent in this activity), but also the decision to stop volunteering. As predictors, they utilized education, assets, income, and health for human capital; for social capital, marital status (also considering the volunteer status of the partner), caregiving to a parent or spouse, children resident in the family, informal help, and work status were used. Moreover, religious attendance was employed to measure cultural capital. McNamara and Gonzales expected human and cultural capital to be positively related to volunteering participation and intensity and negatively to volunteer cessation. On the other hand, the effect of social capital was expected to be mixed, depending on the specific kind of social resource among all those listed. With respect to human and cultural capital, their hypotheses were supported, whereas the results on the role of social capital supported the hypotheses only in part. For example, the authors did not find the expected association between work status and volunteer engagement or cessation.

\section{Motivation of older volunteers}

To satisfy volunteers' motivation has been identified as one of the best ways to improve the match between the demand of voluntary organizations and the supply of older volunteers (Principi, Lamura, \& Jensen, 2014). Most of the available studies on this topic pointed out that volunteer motivation depends on an interplay between altruistic and egoistic elements (e.g., Hustinx et al., 2010). Even if most of the studies on the matter agree that older people are pushed mainly by altruistic rather than by more egoistic motivations (Narushima, 2005). However, due to a preferred participation of older volunteers in the altruistic-type of volunteering (e.g., Morrow-Howell, 2007; Warburton \& Cordingley, 2004), there is currently a growing interest of older people for self-expressive voluntary activities (for example, in the cultural and recreational fields), which implies the presence of a possible set of motivational drivers other than (or complementary to) altruistic values. Furthermore, the diversity among older people is increasing. At 60 years of age, for example, some people may be on the verge of retirement, while others start up a new company. Some are already grandparents, while others (men) become a father again. This means that older people have different interests among themselves, and, therefore, also different motivations regarding the decision to volunteer (Schippers \& Principi, 2014).

Altruistic and egoistic motivations have been proposed as a continuum of volunteer motives. This is according to a unidimensional model (Backman, Wicks, \& Silverberg, 1997) where different motives are supposed to go hand in hand to constitute a unique "rewarding experience" (p. 281) scale (Cnaan \& Goldberg-Glen, 1991), as well as on a model based on a bidimensional perspective (Frisch \& Gerrard, 1981). Other studies have demonstrated that in their decision to give time, volunteers are influenced by the convergence of different kinds of motivations in a multifactor perspective. Altruistic and egoistic motivations can coexist, and the decision to volunteer may also be due to other motivations: for example, the desire to improve social relationships (Prouteau \& Wolff, 2008). 
Unfortunately, the large majority of studies on the motivation to volunteer do not use a validated scale, and they do not discuss the reliability or validity of the measures used (Petriwskyj \& Warburton, 2007). One exception is the Volunteer Function Inventory (VFI) by Clary et al. (1998), which suggested a multifactor motivational perspective to measure motivations to volunteer. Based on functional theories of attitudes elaborated by Smith, Bruner, and White (1956), and Katz (1960), Clary et al. considered motivations as functions to satisfy through volunteering and identified six main different motivational factors related to volunteering. Besides altruistic attitudes (values), they also identified positive strivings for the ego, i.e., motivations to enhance one's own self-esteem (enhancement); motivations to protect the ego from personal problems (protective); motivations to have relationships with others and conform to influences of important others (social); motivations to increase knowledge (understanding); and motivations to increase career opportunities (career).

Several studies have employed the VFI to investigate differences in the motivation to volunteer of older people according to, e.g., age (Davila \& Diaz-Morales, 2009; Ferrari, Loftus, \& Pesek, 1999; Okun \& Schultz, 2003); volunteering status (i.e., volunteer/non volunteer or past-volunteer) (Bowen, Andersen, \& Urban, 2000; Yoshioka, Brown, \& Ashcraft, 2007); country (Principi, Chiatti, \& Lamura, 2012); or work status (Principi, Warburton, Schippers, \& Di Rosa, 2013). The VFI has also been used to study the six different motivational functions as explanatory factors of older volunteers' satisfaction (Clary et al., 1998) and well-being (Ho, You, \& Fung, 2012). In all these studies, out of the six factors, the altruistic attitude always appeared the most important one (i.e., with higher rates on average) for individuals.

\section{Older volunteering: Linking resources to motivations}

Previous studies demonstrated that volunteering of older people depends both on their individual structural capital and on their psychological individual motivations (or needs and motifs important to them). Even if occasionally volunteer motivations were related to some specific forms of capital (for instance, it was found that older volunteers in paid work are more driven by motivations such as the desire to improve their knowledge or career, than retired volunteers-Principi et al., 2013), there is a substantial lack of knowledge on the relationship between older volunteers' whole set of resources in terms of individual human, social, and cultural capital, and their motivation to volunteer. This article adds to the literature because its main aim is to investigate this latter relationship. In the light of its large role in previous studies, the VFI was here employed to measure older volunteers' motivations. With regard to older people that are involved in volunteer activities, our first hypothesis is that not all exogenous forms of capital contribute in the same way to each motivational factor. Rather, different sets of individual capital are associated with one or more motivational factors. For example, we may hypothesize that religiosity (cultural capital) is associated with altruistic motivations to volunteer, while the economic need is associated with the motivation to volunteer to improve one's professional career. The second goal of this article deals with the directions of the associations, i.e., to test in which way the different availability of human, social, and cultural capital (for example, less resources available) is associated with motivations for volunteering. In this perspective, in light of the evidence that older volunteers with more individual capital participate more often in volunteer activities, our second hypothesis is that older volunteers with less availability of capital, and especially human and social capital, have stronger motivations than those with more capital available. Indeed, they can successfully access volunteering only in case of very high motivational drivers, overcoming the barrier represented by the scarce availability of individual resources. Furthermore, they may be particularly motivated to increase the level of the latter through volunteering.

In a context of scarce European evidence on volunteering in older age (Principi, Chiatti, Lamura, \& Frerichs, 2012), this study aims to shed light on the mentioned issues by drawing on a large database of older volunteers from three European countries: the Netherlands, Germany, and Italy. 


\section{Methods}

\section{Data}

This exploratory study relies on data collected on older volunteers (i.e., 50 years and over) between November 2009 and January 2010 by adopting a cluster-sampling method using voluntary organizations as sampling units. Information was gathered in the Netherlands, Germany, and Italy through a self-administered questionnaire, and the final sample consisted of 955 older volunteers.

\section{Measures}

Older volunteers' motivational functions (values, enhancement, protective, understanding, social, and career) were measured by employing the VFI instrument (Clary et al., 1998), which consists in 30 statements on volunteering on which respondents indicate the importance of each one on a 5-point Likert scale, ranging from $1=$ not important to $5=$ very important. Examples of questions measuring the different motivational functions are these: I feel it is important to help others (values); volunteering lets me learn things through direct hands-on experience (understanding); volunteering increases my self-esteem (enhancement); people I know share an interest in community service (social); volunteering helps me work through my own personal problems (protective); I can make new contacts that might help my business or career (career). Translation and back translation was performed where validated versions of the VFI were not available in national languages. A factor analysis with oblique rotation confirmed six factors, and scales' reliability was tested (shown in Principi et al., 2013). The final items employed were 26, after having dropped those with factor loadings below .40 and ambiguous ones (Omoto \& Snyder, 1995). Motivational factors were included in the analyses as continuous variables.

Human capital was measured through the level of education, economic status, and health conditions. To measure the level of education, the International Standard Classification of Education (ISCED) was adopted, and a distinction was made between preprimary; primary or first stage basic and lower secondary or second stage basic education (low education); upper secondary and postsecondary nontertiary education (intermediate) and first and second stages of tertiary education (high education). To obtain self-rated economic-status we asked: "How would you rate your economic status?" Economic status was measured on a 4-point Likert scale from $1=$ low to $4=$ high. For self-rated health we asked: "How is your health?" Responses were measured on a 5-point Likert scale from $1=$ very poor to $5=$ very good. In the present study, we grouped the latter two variables as follows: self-reported economic status medium/low (1-2) and medium/high (3-4); selfrated health poor/very poor (1-2), neither poor nor good (3), good/very good (4-5).

Capital favoring social contacts (i.e., social capital) was measured through the marital status, current care duties towards children or grandchildren under 14 years of age (yes/no), and employment status. Relationships with children were included in previous studies as part of the social capital. Because in this article we are observing older volunteers hence potential grandparents, we extended this concept to relationships with grandchildren by asking "Are you currently caring for children/grandchildren younger than 14?" (yes/no). While Okun and Michel (2006) considered the work for the labor market as human capital, consistent with McNamara and Gonzales (2011), in this study we considered employment status as a form of social capital. We asked older volunteers "Are you currently employed?" (possible answers: no; yes, part-time; yes, full-time).

For measuring cultural capital, in this study we relied on religious attitudes. Religiosity was selfrated by answering this question: "Do you consider yourself a religious person?" Responses were measured on a 4-point scale ranging from 1 (not at all) to 4 (considerably). In this study, the latter variable was grouped in "not at all" (1); somewhat/moderately (2-3) and considerably (4).

As control variables, we included age, gender, and country. These control variables are assumed to be factors that should not be considered as a form of capital. However, as exogenous variables 
they might have an indirect effect on the model (Wilson \& Musick, 1997). We will not discuss these control variables in great detail.

\section{Statistical analyses}

In the descriptive analysis, Pearson chi-square tests and $t$ tests were used to test potential differences between countries in terms of sample characteristics.

The relationship between capital and motivation to volunteer was evaluated in a bivariate analysis using the Kruskal-Wallis equality-of-populations rank test to verify statistical significance.

In order to control for potential bias and confounding effects, multiple regression analysis was performed using the six motivational functions as dependent variables. Given that in previous studies motivational factors were found highly correlated with each other (e.g., Principi et al., 2013), and that we hypothesized that each equation contains different sets of regressors (i.e., forms of capital), we considered it more useful to analyze the six dependent variables using Zellner's seemingly unrelated regression (SUR) instead of estimating the model equation-by-equation using standard ordinary least squares (OLS), because SUR is more efficient. In fact, contrary to OLS, the SUR model implies potentially different sets of exogenous explanatory variables. For this reason, for each dependent variable (besides the control variables), only those forms of individual capital that resulted statistically significant in the bivariate analysis were included. Coefficients and $t$ test $p$ values for each variable are presented. The validity and overall reliability of the model was assessed by means of the diagnostic $F$ test of joint ' 0 ' tests and of the $R^{2}$.

Another distinctive reason for employing the SUR model, is that additional information on residuals can be obtained, i.e., factors that are not included in the model although they are linked to the outcome variables. In this respect, after the coefficients estimation, the correlation matrix of residuals was calculated in order to verify the presence of common underlying characteristics influencing the motivations. The Breusch-Pagan test of independence was used to verify whether the residuals from the six equations are independent from each other.

\section{Sample description}

As shown in Table 1, relative to the availability of capital, there are differences between older volunteers' country samples.

Dutch older volunteers had the highest amount of human capital, Italians the lowest, and the German ones in an intermediate position. With regard to social capital, in the Netherlands we found the highest percentage of married older volunteers, whereas especially in Italy, older volunteers cared for grandchildren. In all countries about $75 \%$ of the sample was not employed, and the percentage of older volunteers employed part-time was particularly low in Italy. As for the availability of cultural capital, the least of nonreligious older volunteers was found in Italy.

The levels of volunteer motivations were different between countries, even if in all countries altruistic motivations (values) had the highest score and career-related motivations the lowest.

Differences between countries were also found relative to older volunteers' age (younger-old volunteers especially in Italy) and gender (although in all countries older volunteers were mainly female, the latter were particularly represented in Germany).

\section{Results}

Bivariate analyses were used as a first step towards understanding whether specific individual resources could be associated with specific types of motivations. As can be observed from Table 2, surprisingly, the motivational function "understanding" was not associated in a bivariate way with any form of individual capital including the educational level. As for the remaining motivational functions, each of them was associated with a specific set of individual capital. 
Table 1. Sample description (\% within countries).

\begin{tabular}{|c|c|c|c|c|}
\hline & Netherlands & Italy & Germany & \\
\hline & $(N=468)$ & $(N=279)$ & $(N=208)$ & $p$ \\
\hline \multicolumn{5}{|l|}{ Demographics } \\
\hline \multicolumn{5}{|l|}{ Age group } \\
\hline $50-64$ & 44.9 & 49.8 & 37.0 & \multirow[t]{3}{*}{ * } \\
\hline $65-74$ & 37.8 & 39.8 & 46.2 & \\
\hline $75+$ & 17.3 & 10.4 & 16.8 & \\
\hline \multicolumn{5}{|l|}{ Gender } \\
\hline Female & 56.0 & 53.8 & 72.4 & *** \\
\hline \multicolumn{5}{|l|}{ Human capital } \\
\hline \multicolumn{5}{|l|}{ Educational level $^{\mathrm{a}}$} \\
\hline Low & 7.9 & 35.4 & 24.0 & \multirow[t]{3}{*}{ *** } \\
\hline Intermediate & 37.8 & 43.7 & 39.2 & \\
\hline High & 54.3 & 20.9 & 36.8 & \\
\hline \multicolumn{5}{|c|}{ Self-reported economic status } \\
\hline Medium-low & 5.2 & 60.2 & 22.7 & \multirow[t]{2}{*}{ *** } \\
\hline Medium-high & 94.8 & 39.8 & 77.3 & \\
\hline \multicolumn{5}{|l|}{ Self-rated health } \\
\hline Poor/very poor & 4.5 & 5.8 & 4.8 & \multirow[t]{3}{*}{$* * *$} \\
\hline Neither poor nor good & 11.6 & 23.4 & 24.3 & \\
\hline Good/very good & 83.9 & 70.8 & 70.9 & \\
\hline \multicolumn{5}{|l|}{ Social capital } \\
\hline \multicolumn{5}{|l|}{ Marital status } \\
\hline Married/cohabiting & 73.8 & 68.6 & 64.4 & \multirow[t]{3}{*}{$*$} \\
\hline Widowed & 10.9 & 17.0 & 15.5 & \\
\hline Divorced/single & 15.3 & 14.4 & 20.3 & \\
\hline \multicolumn{5}{|l|}{ Care for (grand)children } \\
\hline Yes & 8.7 & 30.9 & 21.4 & $* * *$ \\
\hline \multicolumn{5}{|l|}{ Work status } \\
\hline Nonemployed & 73.2 & 74.8 & 75.1 & \multirow[t]{3}{*}{$* *$} \\
\hline Employed part-time & 17.9 & 9.9 & 17.1 & \\
\hline Employed full-time & 8.9 & 15.3 & 7.8 & \\
\hline \multicolumn{5}{|l|}{ Cultural capital } \\
\hline \multicolumn{5}{|l|}{ Religiosity } \\
\hline Not at all & 29.7 & 15.2 & 21.4 & \multirow[t]{3}{*}{$* * *$} \\
\hline Somewhat/moderate & 37.1 & 65.9 & 47.1 & \\
\hline Considerable & 33.2 & 18.9 & 31.5 & \\
\hline \multicolumn{5}{|l|}{ Volunteer motivations ${ }^{b}$} \\
\hline Values & 3.5 & 3.9 & 4.0 & $* * *$ \\
\hline Understanding & 3.1 & 3.3 & 3.5 & $* * *$ \\
\hline Enhancement & 2.9 & 3.2 & 2.9 & $* * *$ \\
\hline Social & 2.5 & 2.8 & 2.3 & $* * *$ \\
\hline Protective & 2.2 & 2.8 & 2.4 & $* * *$ \\
\hline Career & 1.7 & 1.6 & 1.7 & $* * *$ \\
\hline
\end{tabular}

aLow, ISCED 0-2; Intermediate, ISCED 3-4; High, ISCED 5-6. ' ${ }^{\mathrm{b}}$ Mean.

${ }^{*} p<.05 ;{ }^{* *} p<.01 ;{ }^{* *} p<.001$.

Altruistic motivations (values) were associated with indicators of human (educational level and economic status), social (marital status and care for grandchildren) and cultural (religiosity) capital. The results on resources' associations with volunteering for protective reasons are very similar to the former, with the exception of the association with self-rated health instead of care for grandchildren. Volunteering for increasing one's own self-esteem (enhancement) was significantly linked to aspects of human (educational level, economic status, and self-rated health) and social (marital status) capital. Volunteering for social reasons was linked to aspects of human (educational level) and cultural (religiosity) capital. Career motivations were significantly linked to social capital only, and specifically to marital status and work status. 


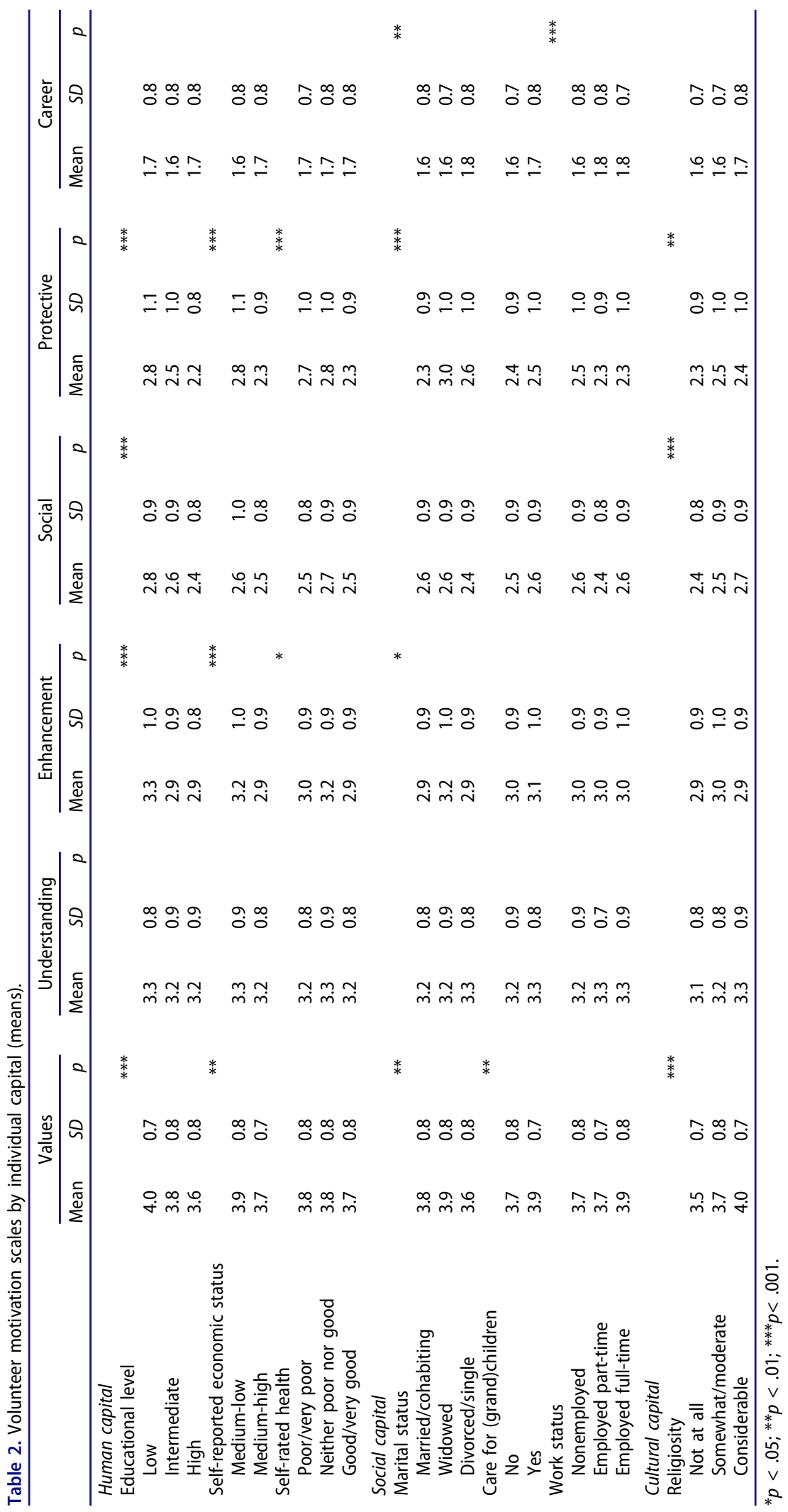


Our second step was to carry out a multivariate analysis, considering for each motivational function different sets of explanatory variables, according to the results of the bivariate analysis. In this perspective, besides the control variables, for each dependent variable, only those forms of individual capital that were statistically significant in the bivariate analysis were included. Table 3 reports the results of the multivariate analysis.

Even if some indicators were almost transversally linked to the motivations to volunteer (e.g., the educational level), in line with our first hypothesis, the results of the analysis showed that different motivational factors are associated with different specific sets of individual capital. Altruistic motivations to volunteer (values) are associated with human (education), social (marital status), as well as cultural (religiosity) capital. Volunteering for social reasons depends mainly on human (education) and cultural (religiosity) capital, while volunteering as a protective activity concerns aspects of human (education and health) and social capital (marital status). Furthermore, volunteering to increase self-esteem depends mainly on human capital (education) and for career-related reasons-mainly on social capital (marital status and work status).

Our second hypothesis that older volunteers with less individual capital have stronger motivations than those with more capital available, is substantially supported. A lower educational level was positively related to altruistic motivations, to volunteering for increasing self-esteem, for social reasons, and to better deal with personal problems. The latter motivations were also positively associated with poorer health conditions and being widowed or single, while being single was also positively associated with career-related motivations. Sometimes, a higher availability of resources positively affected certain types of motivations. For example, being married was associated with altruistic reasons, working parttime (versus nonworking) with career-related reasons, and cultural capital (religiosity) with altruistic and social reasons for volunteering.

Because volunteering for increasing knowledge (understanding) was not associated with any indicator of individual capital in bivariate analyses, we ran the model with control variables only, and these motivations were found to decrease as age increased. The same pattern was observed on volunteering for career-related reasons and to increase self-esteem, while increasing age was positively associated with volunteering to protect the ego from personal problems. The latter motivation was also positively linked to being female, while volunteering for social reasons was linked to being male. The last control variable, country, influenced all motivational functions except for career-related ones.

The R-squared of the six equations were not particularly high (especially the equation on career motivations), implying a rather low proportion of variance explained. In this perspective, by exploring the residuals, the systemic multivariate tool employed in the present work led to additional information on the possible explanatory reasons for the six motivational functions other than the regressors that have been included in the model (i.e., individual capital and control variables). In more detail, the correlation matrix of residuals (Table 4), shows that residuals of each of the six equations concerning types of motivations were correlated (coefficients ranging from .12 to .60). This was further confirmed by the Breusch-Pagan test of independence, which rejected the null hypothesis of no contemporaneous correlation of the errors across equations $(p<.000)$.

The lowest correlation coefficients were found in altruistic motivations (values), while the highest correlation coefficient (i.e., .60) was found between the motivational functions enhancement and protective. This means that $60 \%$ of what was not explained by the model for both of these two equations, is common to these motivational functions.

\section{Discussion}

Volunteering has been recognized as an important field in which active aging can be realized, with benefits both at the societal and the individual level (Walker, 2011). Most of the previous studies on how to enhance volunteering by older people have dealt with individual determinants of volunteering or with their volunteer motivation; and there is a substantial lack of knowledge on the relationship between the former and the latter. For this reason, the present study aimed to provide 
EDUCATIONAL GERONTOLOGY

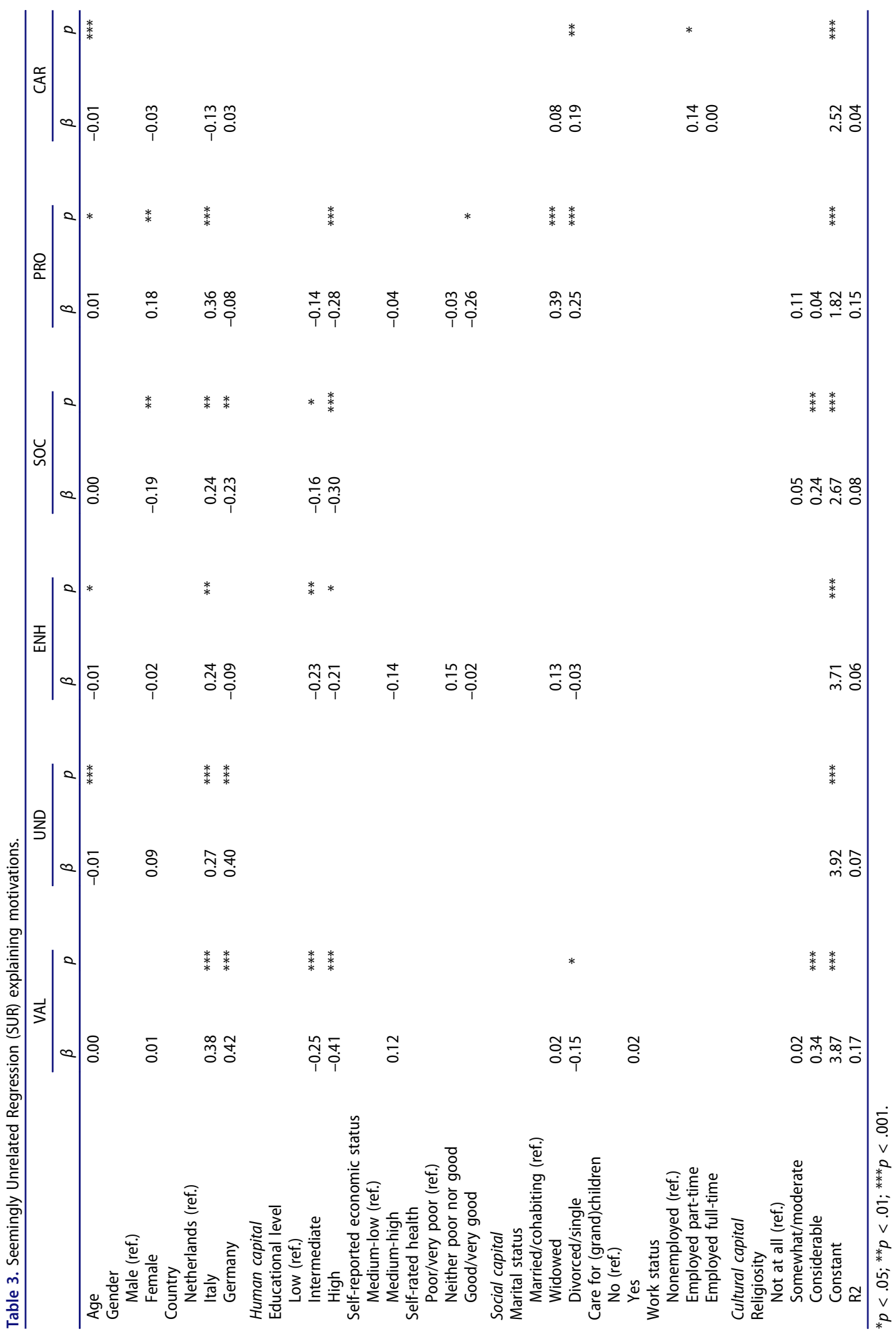


Table 4. Correlation matrix of residuals.

\begin{tabular}{lcccccc}
\hline & Values & Understanding & Enhancement & Social & Protective & Career \\
\hline Values & 1 & & & & & \\
Understanding & 0.26 & 1 & & & & \\
Enhancement & 0.24 & 0.52 & 0.38 & 0.44 & 1 & 1 \\
Social & 0.28 & 0.21 & 0.60 & 0.41 & 0.48 \\
Protective & 0.21 & 0.12 & 0.40 & 0.40 & 1 \\
Career & 0.12 & & & & \\
\hline
\end{tabular}

Note. Breusch-Pagan test of independence: $\mathrm{X}^{2}(10)=1729.262, p<.001$.

stakeholders and policy makers with additional useful information by exploring how individual capital influences different motivational drivers to volunteer.

Our hypotheses that different specific sets of individual capital are associated with different motivational forces, and that older volunteers with less availability of capital have stronger motivations than those with more capital available, were substantially supported.

Human capital was the only kind of individual resource influencing volunteering for increasing one's own self-esteem, in which older people with a lower educational level were more motivated to increase self-esteem. At the educational level, the same pattern was observed concerning volunteering for social and altruistic reasons and for "protective" reasons. The latter motivational factor was also affected by poor health. In light of this and because older people with less resources are less involved in volunteering, stakeholder and policymakers should consider that volunteering may be increased among older people with less resources in terms of education and health, by highlighting that volunteering helps one feel good, helps solve personal problems, improves social life, and it allows one to help other people.

Social capital was the only kind of individual capital influencing volunteering for career-related reasons. Perhaps due to economic reasons, divorced and single older people, rather than married ones, were driven to volunteering in the hope of improving their professional career. This also concerned older people employed part-time, maybe in the attempt to increase their working hours (and hence wage). In line with our hypothesis, being widowed or divorced affected volunteering for avoiding personal problems, probably because older people try to find in volunteer activities the missing support from a partner. In light of this, voluntary organizations and policy makers could more clearly highlight, among non married older people, that volunteering increases the disposition to deal with negative personal life events. Regarding social capital, married older people, rather than divorced ones, were more often found to be driven by altruistic values This is likely because through volunteering divorced people are mainly concentrating on addressing their own needs (e.g., personal or work problems, according to the results of this study), more than on those of other people.

Maybe not surprisingly, religiosity (cultural capital) prompted altruistic motivations (values) and volunteering for social reasons. As expected, a higher amount of cultural capital (religiosity) positively affected these kinds of motivations. Therefore, especially in religious contexts, the importance of devoting time to help people in need and that volunteering means having relationships with other people should be stressed among older individuals.

Quite surprisingly, according to the results of this study, volunteering for increasing knowledge (understanding) was not affected by the forms of capital considered, including the educational level. This may mean that for lower educated older volunteers it is not so important to learn new things (to fill-in the educational gap) through volunteering; rather, other needs may be more important to them, e.g., to feel socially accepted by others despite this condition, or to increase self-esteem (e.g., "volunteering makes me feel important"). Although the aim for knowledge is supposed to decrease in one's older age (Carstensen, Isaacowitz, \& Charles, 1999), future studies should clarify further the relationship between individual resources and this motivational factor. 
This study also showed that the motivation of older people to volunteer not only depends on the forms of individual capital considered in the present study, but also on other underlying elements (identified by residuals) that are partly in common across motivational factors. In this respect, we may notice that altruistic motivations (values), as evidenced by the correlation matrix of residuals, have in general the lowest parts of these residuals in common with other motivations. This may be because the other motivational factors have in common "to gain something in return" from volunteering (e.g., more employment opportunities, increased knowledge or self-esteem, etc.), whereas this aspect is less present when motivations are altruistic. The two motivational factors having the highest part of residual elements in common were volunteering for increasing self-esteem (enhancement) and for avoiding thinking of personal problems (protective)-that is, the two egorelated motivations considered by the VFI. This may mean that the majority of residuals that these two motivational factors have in common could be ascribed to ego-related or psychological factors linked to having low self-esteem and difficulty in dealing with personal problems-for example, a feeling of uselessness and/or depression.

The results obtained on the control variables are substantially in accordance with previous literature (e.g., Okun, Barr, \& Herzog, 1998; Principi, Chiatti, \& Lamura, 2012). As age increases, the decreasing motivations for learning new things and for improving the work situation, and the increasing motivation for emotional goals (protective) can be explained by the socioemotional selectivity theory (Carstensen et al., 1999; Fung, Carstensen, \& Lang, 2001). According to this theory, as people age they are less and less interested in pursuing knowledge but more interested in wishing to pursue emotional goals. However, the desire for personal growth (enhancement) declines with increasing age. The effect of gender-with older males more oriented on social reasons for volunteering, and females on protective reasons, - are in line with previous results (Capanna, Steca, \& Imbimbo, 2002; Okun et al., 1998). Concerning country differences, as found in previous studies (Principi, Chiatti, \& Lamura, 2012), although volunteering rates among the older population are higher in the Netherlands than in Italy and Germany (Principi, Jensen, \& Lamura, 2014), almost all kinds of motivational levels were found to be lower in the Netherlands. This may mean that high rates of volunteering in the Netherlands can be mainly ascribed, compared to other countries, to the welfare regime characteristics including the composition of the welfare mix (Principi, Jensen, \& Lamura, 2014; Salamon \& Anheier, 1998; Warburton \& Jeppsson-Grassman, 2011), than to individual capital and motivation.

While previous studies have proven that individual resources have an impact on volunteering in one's older age in terms of the decision to be a volunteer and of volunteering intensity and cessation, this study demonstrated that individual resources also have a role in explaining the main reasons (i.e., motivational drivers) for volunteering. In light of the call for more applied social research to improve older volunteer's management, especially in terms of recruitment and retention (MorrowHowell, 2010), the results of this study have important implications for organizations and policy makers interested in enhancing volunteering of older people. This is especially true for those elderly with fewer resources available, which specifically participate to a lesser extent in volunteer activities (Cutler \& Hendricks, 2000; Martinson \& Minkler, 2006; Wymer, 1999) and, therefore, may currently miss opportunities to be involved. If volunteering is to be pursued for preventing social exclusion of older people with lower amounts of human and social capital (Ehlers, Naegele, \& Reichert, 2011), organizations need to increase opportunities for such individuals to volunteer by meeting their main motivational drivers. And after recruitment, voluntary organizations should strive to make older volunteers' motivational drivers fulfilled to ensure their retention. For example, they could consider developing more tailored opportunities for involving older volunteers with low educational level, poor health, widowed, divorced or single. In this way, such individuals may be specifically appealed to by the possibilities volunteering offers to satisfy motivational needs such as to increase self-esteem, to deal with personal problems in a better way, and to have satisfying social contacts.

This study has some limitations. An important one is that because the database was designed specifically for studying volunteering of older European people, the results of this study cannot be 
generalized. Indeed, similarly to most of the previous ones using the VFI, this study is not based on a representative sample; therefore, these results should be confirmed through future research. Furthermore, the relationship between individual resources and motivations was studied without a specific focus on other possible important elements, for example, the intensity and the type of volunteer work carried out. These aspects were partially considered by studying residual underlying elements outside of the statistical model employed. However, it would certainly be interesting to explore these aspects further through future research, e.g., to investigate the possible consequences of different combinations of resources and motives for the intensity and/or the type of volunteer work older people may become involved in. Despite these limitations, this article adds important insights on volunteering in one's older age by exploring the relationship between individual resources and motivational forces of older European volunteers.

\section{Funding}

This research was funded by the EU Seventh Framework Programme (FP7/2007-2013) under grant FP7-216289 (ASPA). For more information see: http://www.aspa-eu.com/.

\section{References}

Backman, K. F., Wicks, B., \& Silverberg, K. E. (1997). Co-production of recreation services. Journal of Park and Recreation Administration, 15(3), 58-75.

Becker, G. S. (1964). Human capital. New York, NY: Columbia University Press.

Bowen, D. J., Andersen, R., \& Urban, N. (2000). Volunteerism in a community-based sample of women aged 50 to 80 years. Journal of Applied Social Psychology, 30(9), 1829-1842. doi:10.1111/j.1559-1816.2000.tb02470.x

Capanna, C., Steca, P., \& Imbimbo, A. (2002). Una scala per la misura della motivazione al volontariato [A scale for measuring the motivation to volunteer]. Rassegna di Psicologia, 19(1), 73-90.

Carstensen, L. L., Isaacowitz, D. M., \& Charles, S. T. (1999). Taking time seriously. A theory of socioemotional selectivity. American Psychologist, 54(3), 165-181. doi:10.1037//0003-066x.54.3.165

Choi, L. H. (2003). Factors affecting volunteerism among older adults. Journal of Applied Gerontology, 22(2), $179-196$. doi:10.1177/0733464803022002001

Clary, E. G., Snyder, M., Ridge, R. D., Copeland, J., Stukas, A. A., Haugen, J., \& Miene, P. (1998). Understanding and assessing the motivations of volunteers: A functional approach. Journal of Personality and Social Psychology, 74(6), 1516-1530. doi:10.1037//0022-3514.74.6.1516

Cnaan, R. A., \& Goldberg-Glen, R. S. (1991). Measuring motivation to volunteer in human services. Journal of Applied Behavioral Science, 27(3), 269-284. doi:10.1177/0021886391273003

Cutler, S. J., \& Hendricks, J. (2000). Age differences in voluntary association memberships: Fact or artifacts. Journal of Gerontology: Social Sciences, 55(2), S98-S107. doi:10.1093/geronb/55.2.s98

Davila, M. C., \& Diaz-Morales, J. F. (2009). Age and motives for volunteering: Further evidence. Europe's Journal of Psychology, 5(2), 82-95. doi:10.5964/ejop.v5i2.268

Ehlers, A., Naegele, G., \& Reichert, M. (2011). Volunteering by older people in the EU. Dublin, Ireland: European Foundation for the Improvement of Living and Working Conditions.

Erlinghagen, M., \& Hank, K. (2006). The participation of older Europeans in volunteer work. Ageing e Society, 26(4), 567-584. doi:10.1017/s0144686x06004818

Ferrari, J. R., Loftus, M. M., \& Pesek, J. (1999). Young and older caregivers at homeless animal and human shelters: Selfish and selfless motives in helping others. Journal of Social Distress and the Homeless, 8(1), 37-49.

Frisch, M. B., \& Gerrard, M. (1981). Natural helping systems: Red cross volunteers. American Journal of Community Psychology, 9(5), 567-579. doi:10.1007/bf00896477

Fung, H. H., Carstensen, L. L., \& Lang, F. R. (2001). Age-related patterns in social networks among European Americans and African Americans: Implications for socioemotional selectivity across the life span. International Journal of Aging and Human Development, 52(3), 185-206. doi:10.2190/1abl-9be5-m0x2-lr9v

Ho, Y. W., You, J., \& Fung, H. H. (2012). The moderating role of age in the relationship between volunteering motives and well-being. European Journal of Ageing, 9(4), 319-327. doi:10.1007/s10433-012-0245-5

Hustinx, L., Handy, F., Cnaan, R. A., Brudney, J. L., Pessi, A. B., \& Yamauchi, N. (2010). Social and cultural origins of motivations to volunteer. A comparison of university students in six countries. International Sociology, 25(3), 349382. doi:10.1177/0268580909360297

Institut für Demoskopie Allensbach \& Generali Zukunftsfonds. (2013). Wie ältere Menschen leben, denken und sich engagieren [How older people live, think and engage]. Frankfurt, Germany: Fischer Taschenbuch Verlag. 
Katz, D. (1960). The functional approach to the study of attitudes. Public Opinion Quarterly, 24(2), $163-204$. doi: $10.1086 / 266945$

Martinson, M., \& Minkler, M. (2006). Civic engagement and older adults: A critical perspective. The Gerontologist, 46 (3), 318-324. doi:10.1093/geront/46.3.318

McNamara, T. K., \& Gonzales, E. (2011). Volunteer transitions among older adults: The role of human, social, and cultural capital in later life. The Journals of Gerontology Series B: Psychological Sciences and Social Sciences, 66B(4), 490-501. doi:10.1093/geronb/gbr055

Morrow-Howell, N. (2007). A longer worklife: The new road to volunteering. Generations, 31(1), 63-67.

Morrow-Howell, N. (2010). Volunteering in later life: Research frontiers. The Journals of Gerontology Series B: Psychological Sciences and Social Sciences, 65B(4), 461-469. doi:10.1093/geronb/gbq024

Mutchler, J. E., Burr, J. A., \& Caro, F. G. (2003). From paid worker to volunteer: Leaving the paid workforce and volunteering in later life. Social Forces, 81(4), 1267-1293. doi:10.1353/sof.2003.0067

Narushima, M. (2005). 'Payback time': Community volunteering among older adults as a transformative mechanism. Ageing \& Society, 25(4), 567-584. doi:10.1017/s0144686x05003661

Okun, M. A., Barr, A., \& Herzog, A. R. (1998). Motivation to volunteer by older adults: A test of competing measurement models. Psychology and Aging, 13(4), 608-621. doi:10.1037//0882-7974.13.4.608

Okun, M. A., \& Michel, J. (2006). Sense of Community and being a volunteer among the young-old. Journal of Applied Gerontology, 25(2), 173-188. doi:10.1177/0733464806286710

Okun, M. A., \& Schultz, A. (2003). Age and motives for volunteering: Testing hypotheses derived from socioemotional selectivity theory. Psychology and Aging, 18(2), 231-239. doi:10.1037/0882-7974.18.2.231

Omoto, A. M., \& Snyder, M. (1995). Sustained helping without obligation: Motivation, longevity of service, and perceived attitude change among AIDS volunteers. Journal of Personality and Social Psychology, 68(4), 671-686. doi:10.1037//0022-3514.68.4.671

Petriwskyj, A. M., \& Warburton, J. (2007). Motivations and barriers to volunteering by seniors: A critical review of the literature. The International Journal of Volunteer Administration, 24(6), 3-25.

Polachek, S., \& Siebert, W. S. (1993). The economics of earnings. Cambridge, UK and New York, NY: Cambridge University Press.

Principi, A., Chiatti, C., \& Lamura, G. (2012). Motivations of older volunteers in three European countries. International Journal of Manpower, 33(6), 704-722. doi:10.1108/01437721211261831

Principi, A., Chiatti C., Lamura G., \& Frerichs F. (2012). The engagement of older people in civil society organizations. Educational Gerontology, 38(2), 83-106. doi:10.1080/03601277.2010.515898

Principi, A., Jensen, P. H., \& Lamura, G. (2014). Active ageing: Voluntary work by older people in Europe. Bristol, United Kingdom: The Policy Press.

Principi A., Lamura, G., \& Jensen, P. (2014). Conclusions: Enhancing volunteering by older people in Europe. In A. Principi, P. H. Jensen, \& G. Lamura (Eds), Active ageing: Voluntary work by older people in Europe (pp. 315-342). Bristol, United Kingdom: The Policy Press.

Principi, A., Warburton, J., Schippers, J, \& Di Rosa, M. (2013). The role of work status on European older volunteers' motivation. Research on Aging, 35(6), 710-735. doi:10.1177/0164027512460693

Prouteau, L., \& Wolff, F. C. (2008). On the relational motive for volunteer work. Journal of Economic Psychology, 29 (3), 314-335. doi:10.1016/j.joep.2007.08.001

Salamon, L. M., \& Anheier H. K. (1998). Social origins of civil society: Explaining the nonprofit sector cross-nationally. Voluntas, 9(3), 213-248. doi:

Schippers, J., \& Principi, A. (2014). Organisations' age management of older volunteers: Pointing to the future. In A. Principi, P. H. Jensen, \& G. Lamura (Eds.), Active ageing: Voluntary work by older people in Europe (pp. 297-312). Bristol, United Kingdom: The Policy Press.

Smith, D. H. (1994). Determinants of voluntary association participation and volunteering: A literature review. Nonprofit and Voluntary Sector Quarterly, 23(3), 243-263. doi:10.1177/089976409402300305

Smith, M., Bruner, J., \&White, R. (1956). Opinions and personality. New York, NY: Wiley.

Tang, F. (2006). What resources are needed for volunteerism? A life course perspective. Journal of Applied Gerontology, 25(5), 375-390. doi:10.1177/0733464806292858

Walker, A. (2011). The future of ageing research in Europe: A road map. Sheffield, United Kingdom: University of Sheffield.

Warburton, J., \& Cordingley, S. (2004). The contemporary challenges of volunteering in an ageing Australia. Australian Journal on Volunteering, 9(2), 67-74.

Warburton, J., \& Jeppsson-Grassman, E. (2011). Variations in voluntary association involvement by seniors across different social welfare regimes. International Journal of Social Welfare, 20(2), 180-191.

Warburton, J., Terry, D. J., Rosenman, L. S., \& Shapiro, M. (2001). Differences between older volunteers and nonvolunteers: Attitudinal, normative, and control beliefs. Research on Aging, 23(5), 586-605. doi:10.1177/ 0164027501235004

World Health Organization (WHO) (2002). Active ageing: A policy framework. Geneva, Switzerland: World Health Organization. 
Wilson, J., \& Musick, M. (1997). Who cares? Toward an integrated theory of volunteer work. American Sociological Review, 62(5), 694-713. doi:10.2307/2657355

Wymer, W. W. (1999). Understanding volunteer markets: The case of senior volunteers. Journal of Nonprofit \& Public Sector Marketing, 6(2-3), 1-23. doi:10.1300/j054v06n02_01

Yoshioka, C. F., Brown, W. A., \& Ashcraft, R. F. (2007). A functional approach to senior volunteer and non-volunteer motivations. The International Journal of Volunteer Administration, 24(5), 31-43.

Zaidi, A., \& Stanton, D. (2015). Active ageing index 2014: Analytical Report. Geneva, Switzerland and Brussels, Belgium: UNECE/European Commission. 